\title{
Eficácia de Sistemas de Informação e Percepção de Mudança Organizacional: um Estudo de Caso
}

\author{
Davi Gomes de Andrade \\ James Anthony Falk
}

\section{RESUMO}

Este artigo baseia-se em um estudo de caso que envolve 64 usuários de um Sistema de Informação Hospitalar implantado num grande hospital na cidade do Recife (PE). Parte-se da idéia de que a implantação de um sistema de informação deve ser vista como processo de mudança organizacional, pois tem o potencial de interferir em vários aspectos da organização. Propõe-se a hipótese de que um sistema de informação tende a ser considerado eficaz à medida que é percebido como elemento que contribui para o alcance dos objetivos organizacionais. Neste estudo, encontrou-se uma correlação positiva de 0.5011 entre o grau de eficácia atribuída ao sistema de informação e o nível de melhoria na qualidade percebida do atendimento aos pacientes, sob o ponto de vista de um grupo de usuários que lida mais diretamente com os pacientes nos serviços administrativos. Os resultados sugerem que a relação entre essas variáveis parece ocorrer à medida que os objetivos propostos, aqueles formalmente declarados, são congruentes com os objetivos organizacionais que as pessoas de fato estão buscando na organização, os denominados por Perrow de objetivos operacionais.

Palavras-chaves: mudança organizacional; objetivos organizacionais; tecnologia de informação; sistemas de informação; informática em hospitais.

\begin{abstract}
This paper is based on a case study involving 64 users of a Hospital Information System implanted in a large hospital in the City of Recife, Brazil. It is originated from the idea that the introduction of an information system should be regarded as an organizational change process, since it has a great potential of interfering with various aspects of the organization. The proposed hypothesis is that an information system tends to be considered efficacious when it is perceived as an element that contributes to the fulfilling of institutional objectives. In this study, was observed a positive correlation of 0.5011 between the degree of effectiveness attributed to the information system and the level of improvement in the quality of patient care perceived from the point of view of a group of users that works more directly with the pacients at the administrative tasks. The results suggest that the relationship between the variables may occur according to the degree that the proposed objectives, those formally declared, are congruent with the organizational objectives, those effectively sought by the personnel within the organization, and denominated by Perrow as operational objectives.
\end{abstract}

Key words: organizational change; organizational objectives; information technology; information systems; hospital informatics. 


\section{INTRODUÇÃO}

Os hospitais são organizações complexas e, em virtude de suas características peculiares, são também fortemente afetados por mudanças que ocorrem no ambiente externo, tais como pressões de mercado, políticas governamentais, demandas sociais e, hoje, de forma muito nítida, por aspectos tecnológicos, tanto na área-fim, quanto nas atividades administrativas. No Brasil e no resto do mundo tem havido altos investimentos em tecnologias hospitalares associadas aos serviços médicos (área-fim). Mas, em termos de gestão, na opinião de Jackson da Silva Fisher, da SBC - consultoria paulista especializada em gestão - até mesmo os nossos melhores centros médicos estariam longe dos modelos mundiais de gestão. Segundo ele, "no Brasil, os hospitais estão entre os setores mais atrasados quando se fala em administração" (Fisher apud Vassalo, 1997, p. 89).

Atualmente, são cada vez mais claras as concepções técnicas de qual deve ser o papel de um hospital. Ele é visto, hoje, segundo Juran, como empresa participante do ramo da indústria da saúde, indústria esta que difere das demais em relação à sua história, tecnologia e cultura; mas, quanto aos processos administrativos, isto é, fatores decisivos em relação ao que funciona e não funciona, são semelhantes para todas as indústrias (Berwick et al., 1994).

A tecnologia de informação (TI) também tem merecido uma atenção especial no que tange ao apoio administrativo. No mundo de hoje, seja qual for o ramo de negócio, a empresa competitiva precisa saber usar estrategicamente a informação e a TI, pois ambas têm-se tornado recursos estratégicos para qualquer tipo de organização. Assegurar a perfeita administração da informação médico-hospitalar, administrativa e financeira, tão necessária à moderna gestão de um hospital, constitui algum dos desafios a serem vencidos com a implantação dos chamados Sistemas de Informação Hospitalar (SIH).

Neste estudo, é tratada a questão da TI utilizada na gestão administrativa de um hospital, não da informática médica, usada na atividade-fim. Mais especificamente, trata-se da implantação de um Sistema de Informação Hospitalar num grande hospital localizado no Recife (PE). 


\section{Os Objetivos Organizacionais em Face dos Processos de INFORMATIZAÇÃO}

O sucesso ou fracasso de um sistema de informação (SI) pode estar relacionado ao seu próprio processo de implantação, que envolve outros aspectos, além daqueles meramente tecnológicos, entre os quais a forte participação dos usuários. Albertin (1995, p. 61) destaca que o "SI tem se tornado um componente crítico do planejamento estratégico e da vantagem competitiva das organizações, levando os executivos a uma maior preocupação com a administração de informática". Após o período mais crítico de desenvolvimento, testes, adaptação e/ou implantação de um sistema de informação, como saber se tudo valeu a pena? Os benefícios compensam os custos? Os objetivos inicialmente definidos foram atingidos? Qual o nível de satisfação dos usuários?

Parece difícil mensurar os retornos com os gastos em informática. Paul Strassmann, autor do livro lançado em 1997, nos Estados Unidos, The Squandered Computer (O Computador Desperdiçado), discute o chamado paradoxo dos computadores ou paradoxo da produtividade. Ele analisou dados experimentais de cerca de 500 empresas desde 1980 e a sua primeira conclusão foi devastadora: "não há a menor relação entre quanto uma empresa investe em tecnologia da informação e seu sucesso econômico, seja ele medido como lucro, crescimento ou produtividade" (Strassmann apud Gurovitz, 1997, p. 86). Em síntese, altos investimentos em TI podem significar inovação, mas também desperdício. Gastar pouco pode ser sinônimo de prudência, mas também de atraso. Resta então atentar para o bom senso, pois em matéria de TI, o importante não é quanto se gasta, mas como se gasta. As decisões em relação à TI, portanto, são difíceis de serem tomadas, podendo envolver altos custos e os resultados nem sempre vêm a contento e no curto prazo.

Campos Filho (1994) conceitua o SI - do ponto de vista do seu gerenciamento - como uma combinação estruturada entre o componente práticas de trabalho (os métodos usados pelos recursos humanos para desempenhar suas atividades) com outros três componentes: informação (o conjunto de dados com forma e conteúdo adequados para um determinado uso); recursos humanos (quem coleta, processa, recupera e utiliza os dados); e tecnologias de informação (o conjunto de hardware e software que executa as tarefas de processamento das informações dos SI's). Tudo, porém, deve ser organizado e orientado para que os objetivos organizacionais sejam atendidos da melhor forma possível. Apesar de não serem propriamente um componente do SI, os objetivos organizacionais determinam as práticas de trabalho, provendo os critérios que levam à decisão de como e quando essas práticas devem ser alteradas e adaptadas. Nesta 
concepção mais abrangente de um SI, todos os componentes são importantes, porém se enfatiza que "o ponto focal para o entendimento da natureza do SI são as práticas de trabalho, e não a tecnologia da informação, como pode parecer à primeira vista" (Campos Filho, 1994, p. 34).

Embora a TI seja importante para apoiar os processos dinâmicos no tratamento da informação, o seu valor depende da informação e do papel que ela (a informação) desempenha nas organizações. Segundo McGee (1999, p. 5), "a tecnologia utilizada para apoiar esses processos é consideravelmente menos importante do que a informação contida nos sistemas". Um problema freqüente no desenvolvimento, implantação e gerenciamento de um SI é a colisão frontal entre a visão dos usuários e clientes, muito focalizada nas práticas de trabalho, e as tendências dos staffs técnicos em supervalorizar as tecnologias. "Um viés muito comum e sério que as empresas e os profissionais da área de informática apresentam é ficarem maravilhados com os avanços tecnológicos, com os novos lançamentos de equipamentos, softwares e comunicações, perdendo completamente o foco no cliente e nos benefícios que a tecnologia realmente pode trazer" (Shiozawa, 1993, p. 48).

Na opinião de Marinho (1990), a organização moderna caracteriza-se pela presença de objetivos organizacionais e por um esforço conjunto por vários indivíduos que buscam atingi-los. A maior parte das atividades desenvolvidas em uma organização pode ser relacionada aos seus objetivos. Essa autora analisa os objetivos organizacionais sob cinco perspectivas sociológicas: racional, funcionalista, tecnológica, na abordagem da teoria do processo decisório e na abordagem da economia política, destacando-se aqui as três primeiras.

$\mathrm{Na}$ perspectiva racional, dita weberiana, os objetivos fornecem, de forma clara e inequívoca, uma direção a ser tomada, devendo ser formalmente estabelecidos no topo da hierarquia. Trata-se aqui dos objetivos formais ou declarados.

Na perspectiva funcional ou sistêmica, os objetivos organizacionais não são dados, ou seja, estabelecidos e estáticos. Pelo contrário, "são o resultado das interações da organização com o seu ambiente e um produto muito mais de pontos de vista conflitivos e contraditórios do que dos consensuais e não contraditórios" (Marinho, 1990, p. 12). Nesta abordagem, a organização é vista como um sistema aberto que interage com o ambiente, do mesmo modo que as partes que a compõem interagem entre si, de forma que a busca em direção ao equilíbrio, a necessidade de auto-sustentação (de sobrevivência) constitui o principal objetivo organizacional, sendo força tão importante quanto aquelas dos objetivos formais.

Perrow (apud Marinho, 1990, p. 13), considerando que os objetivos são aspectos variáveis e não elementos fixos de uma organização, introduziu o conceito de 
objetivos operacionais como sendo "aqueles que dizem o que a organização está tentando realmente fazer, independentemente do que é declarado como sendo seus fins". Tais objetivos se referem aos fins de grupos específicos dentro da organização, não importando em qual nível hierárquico esses grupos estejam. Nessa perspectiva, dita tecnológica, os objetivos operacionais são presumíveis a partir do conhecimento das principais tarefas de uma organização e dos grupos que as controlam. Em outras palavras, esses objetivos são formulados pelos grupos que dominam a tecnologia que ora influencia a estruturação interna de poder. Perrow (apud Marinho, 1990, p. 14) entende por tecnologia "as ações que um indivíduo faz sobre um objeto, com ou sem a ajuda de ferramenta ou instrumentos mecânicos para transformá-lo".

\section{A Utilização da Tecnologia de Informação em Hospitais}

O desenvolvimento de SIH's, conforme descreve Johanston (1993), começou nos anos 60, nos grandes hospitais-escola nos Estados Unidos e na Europa, coincidindo com o período em que se inicia também o uso dos computadores. Ilha (1993) afirma que as primeiras aplicações na área hospitalar ou de registro clínico são desta época, quando surgiram o COSTAR, o Technicom Medical Information System (TMS) e, na década seguinte, os sistemas HELP, PROMIS e Regenstrief Medical Record System. Sendo o custo do hardware e do software muito elevados naquele momento, apenas as grandes instituições podiam arcar com os altos investimentos para terem um computador central de grande porte (os chamados mainframes), por meio do qual todos os setores de um hospital eram interligados e onde todas as bases de dados eram armazenadas.

No final da década de 70 e início dos anos 80 , o avanço tecnológico já tinha conseguido baratear os custos e até os departamentos conseguiam adquirir minicomputadores. Ainda no final dos anos 80, até mesmo microcomputadores ou Personal Computer ( $P C$ 's) se juntaram ao arsenal usado pelos hospitais para informatização de seus serviços.

$\mathrm{O}$ aumento da capacidade de processamento dos micro e minicomputadores, associado à redução dos preços desses equipamentos, tem contribuído para que os hospitais implantem sistemas descentralizados ou distribuídos, que se caracterizam pela existência de computadores departamentais (laboratório, farmácia, enfermagem etc.); embora preservando a autonomia local, podem eles funcionar de forma integrada, mediante uma rede local de computadores (Local Area Network - LAN). Sabbatini e Ortiz (1994) acreditam que as LAN's constituem a solução tecnológica mais barata e eficiente existente atualmente 
para uma informatização integrada que abrange um ambiente distribuído e disperso. Existe sempre uma ou mais maneiras viáveis de se implementar a informatização de um hospital. Cada caso é um caso que deve ser analisado cuidadosamente, a fim de se indicar a melhor solução em hardware e software, de acordo com a disponibilidade financeira e as prioridades estabelecidas pela direção de cada hospital.

No Brasil, a utilização da TI na gestão hospitalar tem evoluído de uma situação em que se usava o computador para realizar tarefas relativamente simples e isoladas entre si, até o contexto atual em que se busca a integração dos diversos setores que geram e/ou utilizam as informações dentro de um hospital. Com a necessidade cada vez maior de agilidade e rapidez nas decisões e de se compartilhar informações de maneira segura, pode-se dizer que um SIH se tornou algo indispensável para se alcançar a eficiência administrativa nos hospitais. A utilização de computadores na área de saúde é um dos segmentos de mercado que mais crescem atualmente. O baixo custo de hardware e a oferta de diversos softwares especializados, vêm despertando a comunidade médica para a importância da informática, fazendo-lhe ver como ela pode aumentar a sua produtividade e, conseqüentemente, os seus benefícios. Apesar disso, os investimentos para se desenvolver ou implantar um SIH num hospital de médio ou grande porte ainda são consideravelmente altos em equipamentos, softwares e serviços. Embora existam diversas empresas na área de informática dedicadas ao setor de hospitais, ainda há dificuldades em se encontrar produtos adequados e flexíveis que atendam às necessidades de grandes hospitais, sendo difícil a escolha de um software que atenda aos requisitos de especificação dos gestores e se enquadre no perfil das novas tendências tecnológicas.

Um SIH deve facilitar a coleta, o armazenamento, o processamento e a integração das informações entre os diversos setores (área-fim e área-meio), de modo que a instituição funcione harmoniosamente no cumprimento de seus objetivos. Em um SIH, o processamento de dados ocorre em menor escala, pois a maior demanda é por armazenamento e busca imediata da informação. Esses sistemas precisam ser ágeis para armazenar grandes volumes de dados, podendo também fornecer grandes quantidades de informações em pequeno espaço de tempo. Komagata (19__ ) ressalta que hoje a característica mais importante de um sistema de informação hospitalar é a sua capacidade de integrar todos os setores informatizados.

Os clientes internos/externos esperam de um hospital um atendimento rápido e informações seguras, atualizadas e consistentes, desde a entrada até à saída de um paciente do hospital. Um SIH computadorizado, integrando as diversas áreas de um hospital, possibilita o acesso rápido e seguro às informações em tempo 
real, deixando no cliente uma idéia positiva da organização. Falk e Carvalho (1999) ressaltam que o primeiro contato do paciente em um hospital é com os serviços de recepção geral da instituição (Admissão/Abertura de Prontuário Médico/Setor de Convênio ou Caução), quando ocorre um dos momentos da verdade, expressão popularizada por Carlzon e descrita por Albrecht (1994, p. 10) como sendo "qualquer episódio onde o cliente entra em contato com qualquer aspecto da organização e cria uma opinião com relação à qualidade do serviço".

$\mathrm{Na}$ área de serviços é mais difícil aplicar-se conceitos de qualidade, porque serviço é uma entidade mais intangível. A qualidade a que nos referimos neste trabalho é aquela associada a um produto ou serviço e que pode ser percebida sob diversas óticas ou dimensões. Garvin (1992), em sua obra Gerenciando a Qualidade, descreve cinco abordagens para a definição de qualidade: (1) transcendente - aquela subjetiva que não se pode definir, mas se sabe o que é; (2) baseada no produto - baseada em atributos relevantes do produto; (3) baseada no usuário - aquela que "está diante dos olhos de quem observa", levando à noção de "pontos ideais" que proporcionem a maior satisfação das necessidades (literatura de marketing) e ligada ao conceito de "adequação ao uso" (literatura de administração de operações); (4) baseada na produção - "conformidade com as especificações" (do lado da oferta); (5) baseada no valor - relacionada a preços e custos.

O uso de tecnologias em áreas de prestação de serviços, entre elas a TI, deve ser orientado para o melhor atendimento ao cliente (interno e/ou externo). No caso dos hospitais, quem não está servindo aos pacientes deve estar servindo àqueles que estão diretamente prestando o serviço. A TI deve ser usada de forma inteligente, de modo a refletir-se na melhoria das atividades complementares, as quais, indiretamente, podem contribuir para uma melhor prestação de serviços nas atividades-fim. Na área de saúde, como afirma Ilha (1993), "mesmo a informatização de caráter administrativo traz benefícios quanto à qualidade de atendimento prestada".

\section{O Processo de Escolha de um Sistema de Informação}

É importante conhecer a experiência de outras instituições, quando no processo de escolha de um sistema de informação, porém, como ressalta Komagata (19__), "não se pode simplesmente importar soluções prontas para o ambiente hospitalar". Embora não exista uma metodologia padrão para a escolha de software, Komagata (19__ ) propõe a divisão do processo de escolha em três partes: (1) Definição da instituição: objetivos a serem alcançados com a informatização; (2) Análise 
do mercado de sistemas: contato com vários fornecedores para um estudo preliminar das características de cada produto, independentemente de seu ajuste ou não à instituição; (3) Avaliação dos produtos: máximo empenho para se chegar à escolha do produto que melhor atenda aos objetivos pré-definidos da informatização; isso envolve verificar referências dos candidatos, demonstração do produto, visitas a locais já informatizados e avaliação de impactos.

A atualização tecnológica é um aspecto muito importante, visto que, nos últimos anos, os equipamentos e as plataformas de sistemas operacionais se tornam obsoletos com crescente rapidez, em média a cada cinco anos. A satisfação do usuário pode depender das facilidades de uso proporcionadas pela tecnologia. As plataformas de hardware e software, dentro de um processo de seleção de um sistema hospitalar, devem ser consideradas nas fases mais precoces do processo de seleção, devendo ser colocadas como fator eliminatório para os fornecedores existentes no mercado, pois um fornecedor que se mantenha à margem desse processo poderá condenar o hospital à depreciação do seu patrimônio de informática. Não se deve, contudo, privilegiar em excesso o aspecto tecnológico em detrimento das qualidades inerentes do SI em resolver problemas e controlar processos.

\section{Avaliação da Eficácia dos Sistemas de Informação}

A norma ISO 9126 descreve o modelo de qualidade de software, incluindo critérios objetivos e também subjetivos, numa escala menor. Ela define seis características de qualidade e subcaracterísticas associadas a essas características (vide Quadro 1).

O diagnóstico da qualidade e produtividade em software ainda é pouco utilizado no Brasil. Uma pesquisa realizada em 1997, que envolveu 589 empresas, mostrou que $81,8 \%$ delas não conheciam as normas para qualidade; $16,8 \%$ conheciam, mas não usavam e apenas $0,2 \%$ conheciam e usavam (Rocha, 1998).

Conforme Dias (1993, p. 163), "não existe uma medida objetiva e direta para medir a eficácia de um sistema de informação. Em geral, ela é avaliada pela capacidade do sistema desenvolvido apoiar os objetivos da empresa, segundo a percepção dos usuários do sistema". Avaliar e medir os resultados de um SI, porém, "não é um processo fácil e muito menos de rápido entendimento e assimilação porque envolve aspectos comportamentais entre outros fatores" (Rebouças apud Brodebeck, 1995, p. 81). 


\section{Quadro 1: Caraterísticas de um Software de Qualidade}

\begin{tabular}{|c|c|c|}
\hline Caracteristica & Subcaracteristica & Pergunta chave para subcaracteristica \\
\hline \multirow{5}{*}{$\begin{array}{l}\text { Funcionalidade } \\
\text { (satifaz às } \\
\text { recessidades?) }\end{array}$} & Adequação & Propõe-se a fazer o que é apropriado? \\
\hline & Aourácia & Faz o que fi proposto de foml coneta? \\
\hline & Irteroperab iidade & Interage comos sistemas especificados? \\
\hline & Confomidade & Está de acondo com as nomas, bi etc? \\
\hline & $\begin{array}{l}\text { Segurança de } \\
\text { acesso }\end{array}$ & Evita acesso rão autovizado aos dados? \\
\hline \multirow{3}{*}{$\begin{array}{l}\text { Confiabililade } \\
\text { (é irume a fallas?) }\end{array}$} & Maturitade & Com que freqiê̂ncia apresenta fallas? \\
\hline & Tolerância a fallas & Oconendo flles, como ele reage? \\
\hline & Recuperabilidade & $\begin{array}{l}\text { É capaz de recuperar dados em caso de } \\
\text { falla? }\end{array}$ \\
\hline \multirow{3}{*}{$\begin{array}{l}\text { Usabilidade } \\
\text { (é fä́cil de usar?) }\end{array}$} & Intelegbilitade & É ficl enterder o corceito e a aplicação? \\
\hline & Apreensbitidade & É ficl aprender a usar? \\
\hline & Operaciomalidade & É ficil de operar e controlar? \\
\hline \multirow{2}{*}{$\begin{array}{l}\text { Eficiência } \\
\text { (é rápido e enxub?) }\end{array}$} & Terrqo & $\begin{array}{l}\text { Qual é o termo de resposta, a vebcilade de } \\
\text { execução? }\end{array}$ \\
\hline & Recursos & Quarto recurso usa? Durarte quarto termpo? \\
\hline \multirow{4}{*}{$\begin{array}{l}\text { Manutenbitidade } \\
\text { (é fácil de rodificar?) }\end{array}$} & Aralisabilitade & $\begin{array}{l}\text { É ficil de encontraruma falla, quando } \\
\text { ocone? }\end{array}$ \\
\hline & Modificabilidade & É ficl modificar e adaptar? \\
\hline & Estabilitade & Há gande rico quardo se fazem alterações? \\
\hline & Tes tbibidade & É facil testar quando se faxm alteragões? \\
\hline \multirow{4}{*}{$\begin{array}{l}\text { Portabilidade } \\
\text { (é fácil de usar em } \\
\text { outoo anbiente?) }\end{array}$} & Adaptzb ilidade & É ficil adaptar a outros antiertes? \\
\hline & $\begin{array}{l}\text { Capacidade para ser } \\
\text { instalado }\end{array}$ & É ficil instalar em outros anbiertes? \\
\hline & Conformidade & $\begin{array}{l}\text { Está de acordo com padröes de } \\
\text { portab iidade? }\end{array}$ \\
\hline & $\begin{array}{l}\text { Capacilade para } \\
\text { ubstiniri }\end{array}$ & É ficil usar para swstinir outro? \\
\hline
\end{tabular}


Em muitos casos, prefere-se avaliar o impacto do SI identificando-se os benefícios alcançados a partir dele, os quais podem ser classificados em tangíveis e intangíveis. Os benefícios tangíveis são aqueles que trazem à organização vantagens econômicas quantificáveis, em decorrência do uso do SI (Kendall e Kendall apud Freitas, 1994). Alguns desses benefícios podem ser a dinamização do processo, tais como melhorias no fluxo de trabalho e no fluxo de material, a informação mais pontual e, conseqüentemente, a redução no tempo de execução de uma tarefa, a redução de procedimentos e a redução de papel. Os benefícios intangíveis são difíceis de quantificar, embora igualmente importantes. Entre eles pode-se enumerar: a melhoria no processo de tomada de decisão, a redução de erros e conseqüentemente o aumento da precisão, a melhoria dos serviços aos clientes, a imagem dos negócios etc.

Dias (1993) avaliou a eficácia de sistemas de informação, considerando duas dimensões: satisfação do usuário e qualidade das informações geradas pelos sistemas. Segundo a orientação de Freitas et al. (1994), um SI pode ser eficaz por duas razões: a facilidade de uso (atributos ligados ao sistema) e a utilidade do sistema (no que diz respeito às expectativas dos usuários). No modelo global de Freitas et al. (1994) para avaliação da eficácia de SI's, o que efetivamente interessa na avaliação de um SI é saber, do ponto de vista organizacional e funcional, se ele é útil e, do ponto de vista do usuário, se ele é fácil de usar. Esses dois pilares são distintos, não excludentes, podendo existir sistemas fáceis de usar (ótimo desempenho, ótima interface de comunicação com o usuário), mas que não sejam úteis, isto é, não atendam às necessidades de controle da informação. Dependendo da situação, das características do software e da credibilidade do seu desenvolvedor, entre outras razões, esses aspectos podem até ficar em segundo plano, a exemplo do que ocorreu neste estudo de caso.

No presente estudo, considerou-se a dimensão satisfação do usuário como um dos componentes da medida de eficácia do SI, por se entender que a facilidade de uso (Freitas et al., 1994) está contida no que Dias (1993) chama de satisfação do usuário, uma vez que os aspectos ligados à facilidade de uso contribuem também para a satisfação do usuário. O outro componente da medida de eficácia foi a utilidade do sistema. O SI contribui para o processo de decisão do usuário final, à medida que suas saídas forem úteis para a definição de ações, de modo que o seu uso possibilite também a melhoria de outros fatores organizacionais, contribuindo para a solução de problemas e reduzindo o tempo gasto na execução das tarefas.

Freitas et al. (1994, p. 36) ressaltam ainda: "Em muitos casos é preferível ava- 
liar o impacto do SI através da identificação dos seus benefícios (com o cuidado de se dar destaque àqueles que, pelos seus reflexos na organização, justificam plenamente a adoção do sistema)". Neste estudo, foi declarado pelo superintendente da organização que um dos principais objetivos pretendidos com a informatização era tornar mais eficaz a gestão administrativa, de modo a melhorar a qualidade dos serviços prestados aos pacientes, pois "o cliente pena pela falta da informatização" (Entrevista).

O presente trabalho se propõe então a testar a hipótese assim enunciada:

- A eficácia atribuída a um sistema de informação está associada à percepção de que ele contribui para a realização de objetivos organizacionais.

Esta hipótese é proposta a partir de duas idéias básicas identificadas na literatura pesquisada.

. Qual o objetivo da implantação de um sistema de informação? "Implantá-los é equivalente a realizar uma intervenção, visando uma mudança organizacional, que afetará os subsistemas técnico, social e político da organização" (Dias, 1993, p. 164). Segundo Campos Filho (1994), em última análise, os usuários de um sistema de informação (profissionais, executivos e analistas) almejam, por meio do manuseio da informação, atingir os objetivos organizacionais.

\section{. Como avaliar os resultados da implantação de um sistema de informa-} ção? "O sucesso final de qualquer objetivo de mudança é, naturalmente, medido pelo grau em que os próprios objetivos são alcançados" (Shirley, 1976).

\section{Metodologia da Pesquisa}

Este estudo pode ser classificado como uma pesquisa aplicada (vinculada a uma instituição) e empírica (quanto ao gênero), sendo de caráter descritivo e avaliativo, em que se pretendeu atingir os seguintes objetivos específicos.

. Descrever a implantação de um sistema de informação em um hospital, caracterizando-a como um processo de mudança.

- Avaliar a eficácia do sistema implantado, na perspectiva dos usuários que o operam.

- Verificar até que ponto a avaliação da eficácia do sistema de informação, sob o ponto de vista dos usuários, está associada aos níveis de melhoria na qualidade 
percebida do atendimento ao paciente.

Nesta pesquisa, adotou-se a estratégia de estudo de caso pelo fato de se pretender estudar com profundidade um evento contemporâneo, a informatização numa organização hospitalar. Conforme Yin (1994, p. 1), estudos de caso são cada vez mais usados como ferramentas de pesquisa e, em geral, "são estratégias preferidas quando as questões Como? e Por que? são propostas, quando o investigador tem pouco controle sobre o evento e quando é focalizado um fenômeno atual dentro de algum contexto de vida real". A pesquisa descreve como se deu a informatização nesse hospital, buscando identificar os critérios que foram utilizados na seleção do sistema de informação, os problemas enfrentados na sua introdução, as escolhas gerenciais adotadas etc.

Para que fossem atingidos os objetivos específicos propostos, achou-se conveniente a utilização de métodos múltiplos. Quanto ao primeiro objetivo, foram utilizados métodos qualitativos, buscando-se resgatar os porquês, as explicações para os fatos, na busca de se verificar até que ponto as conclusões encontradas na literatura se aplicam a este caso. As técnicas de coleta de dados utilizadas foram entrevistas, observação não participante e análise de documentos. Foram utilizadas duas técnicas de entrevista, citadas por Richardson (1989): a entrevista dirigida e a guiada. Nas do primeiro tipo participaram alguns dos principais envolvidos nas decisões referentes à informatização, entre eles o superintendente e o assessor de informática (ambos da gestão 97-98) e a relações públicas de um dos principais departamentos do hospital. Foram seis as entrevistas do tipo guiada (mais informais), tendo a participação de funcionários e chefes de setores. Esta pesquisa foi iniciada em 1997; deu-se-lhe um corte seccional com perspectiva longitudinal.

Para se atingir o segundo objetivo específico, foi distribuído um questionário de pesquisa aos chefes e funcionários dos setores informatizados (num total de 98 usuários), sendo devolvidos 64 deles. A primeira parte do questionário de pesquisa constou de 15 itens referentes à satisfação do usuário. A segunda parte foi composta por 9 itens referentes à utilidade do sistema. Foi utilizada nos dois construtos uma pergunta de fechamento para validação do instrumento.

O questionário usado nesta pesquisa baseou-se nos itens propostos por Freitas et al. (1994) e nos itens da pesquisa de Dias (1993), fazendo-se adaptações e incluindo-se novos itens propostos na literatura de engenharia de software (Pressman, 1995). Tanto Freitas et al. (1994) quanto Dias (1993) tomaram por base o questionário desenvolvido por Jenkins e Ricketts em 1985: Development of an MIS Satisfaction Questionnaire: An instrument for Evaluating User Satisfaction with Turnkey Decision Support. 
A variável eficácia do sistema foi medida pelo escore resultante da soma dos pontos atribuídos aos 15 itens referentes à satisfação do usuário e aos 9 itens referentes à utilidade do sistemas. Para operacionalizar o terceiro objetivo específico desta pesquisa, incluímos no questionário as seguintes perguntas.

\section{Você acha que com a informatização a qualidade dos serviços prestados} aos pacientes:

$$
\square \text { não mudou } \square \text { melhorou } \square \text { piorou }
$$

\section{Caso tenha respondido que "melhorou", na sua opinião, essa melhoria foi:}

muito pequena $\square \square \square \square \square$ muito grande

\section{5}

A análise dos dados foi mais acentuada na parte qualitativa, no que se refere às entrevistas e observações, que buscaram descrever o processo de informatização. No tocante aos dados coletados para se atingir o segundo e terceiro objetivo específico, foi utilizada uma análise quantitativa, montando-se um banco de dados (EXCEL 97). Foram utilizados os seguintes métodos estatísticos.

. Regressão: ferramenta de análise de dados que executa uma análise de regressão linear, usando o método dos mínimos quadrados para ajustar uma linha por meio de um conjunto de observações. Pode-se usar esta ferramenta para analisar como uma variável dependente é afetada pelos valores de uma ou mais variáveis independentes; por exemplo, como a percepção de eficácia do sistema de informação é afetada pela percepção de melhoria no atendimento (utilizou-se um nível de confiança de 95\%).

. Teste-T: duas amostras presumindo variâncias equivalentes. Ferramenta de análise de dados usada para identificar se a diferença de médias entre duas amostras é ou não significativa.

Um dos benefícios do emprego conjunto dos métodos qualitativo e quantitativo, indicados por Duffy (apud Neves, 1996, p. 106), é a "possibilidade de congregar controle dos vieses (pelos métodos quantitativos) com compreensão da perspectiva dos agentes envolvidos no fenômeno (pelos métodos qualitativos)".

\section{O Processo de Mudança}


A tecnologia de um modo geral exerce um papel de destaque como influenciadora de mudanças e, a TI em especial, é também considerada como um fator potenciador de desenvolvimento e fator facilitador da atividade administrativa, sendo, segundo Torres (1995), o principal elemento de mudança nos dias de hoje, por ter uma capacidade de integração intra e interorganizacional; mas a informatização, por si só, não soluciona problemas e não funciona em nenhuma estrutura desorganizada, pois quem faz a organização e a administração de uma estrutura são as pessoas, não as máquinas ou o software. Se a administração de uma empresa for um caos, o máximo que se irá conseguir é o caos informatizado. O que a TI faz por uma empresa é oferecer recursos fantásticos para melhor aproveitamento de todos os demais recursos.

A organização sob estudo, fundada há mais de 50 anos, caracteriza-se como hospital especializado no diagnóstico e tratamento de um tipo grave de doença. Nos últimos anos, a demanda por seus serviços tem crescido intensivamente, principalmente, no que tange ao atendimento dos pacientes do Sistema Único de Saúde (SUS). Há alguns anos, mais notadamente a partir de 1995, essa organização vem implementando mudanças, algumas de forte impacto, na tentativa de melhor se adaptar a um novo contexto social, econômico e financeiro. Até à gestão do biênio 95-96, pode-se analisar o seu processo de mudança como sendo emergente. Wilson (1992) caracteriza como emergente um fenômeno que irrompe das interações históricas, econômicas, políticas e de negócios, sendo conseqüência do jogo do poder que induz as mudanças. Motta (1999) chama a isto de adaptação reativa.

Torres (1995) considera a mudança tecnológica como uma transformação revolucionária, pois nesse tipo de processo a mudança costuma ser de alta magnitude e ocorre geralmente num espaço de tempo relativamente curto. Devido aos altos investimentos em equipamentos, consultorias e serviços, os gestores tendem a pressionar para que os resultados com o uso da TI apareçam o mais rapidamente possível, justificando assim os investimentos; mas os resultados nem sempre surgem no curto prazo.

Leavitt ressalta que os elementos organizacionais devem ser vistos como um sistema constituído por estrutura, tecnologia, tarefa e pessoal, de modo que qualquer alteração em um desses elementos, provavelmente, afetará os demais. Quando, na mudança tecnológica, os estudos evidenciam que se tende a fazer ajustes na estrutura, podendo ocorrer que tal mudança implique novas relações dos indivíduos com suas tarefas.

A organização descrita neste estudo ressentia-se de um controle mais eficaz dos seus recursos; seus gestores não podiam obter respostas rápidas e seguras para a tomada de decisão em certas áreas, tais como Almoxarifado, Farmácia, 
Pessoal etc. A necessidade de tornar mais eficaz a gestão administrativa motivou, ainda na gestão 95-96, a decisão de se informatizar todas as funções administrativas do hospital. Pretendia-se, a partir da informatização, dar prosseguimento às mudanças, ora em andamento; mas, pelo menos no primeiro ano, a informatização evoluiu muito pouco, gerando-se muitos conflitos internos e externos. Parece ter faltado também um maior envolvimento por parte dos gestores de então.

Um aspecto importante no processo de mudança é o apoio da alta administração. No caso da administração da informática nas organizações, que envolve, entre outras coisas, a implantação de sistemas de informação, Albertin (1995) destaca o apoio da alta gerência (incluindo-se sua participação, envolvimento, estilo gerencial, fornecimento e recepção de informações, apoio e compromissos) como um dos mais importantes fatores críticos de sucesso. Ele identificou quatro cenários típicos de atitudes da alta gerência quanto à implantação da TI: os dependentes, os céticos, os envolvidos e os positivos.

O presente estudo analisa que os gestores do início da informatização talvez não achassem necessário ter grande participação nas decisões ligadas à TI, colocando-se como apoio à sua implantação (os dependentes). Essa gestão foi marcada por uma situação de crise, sob o ponto de vista administrativo, financeiro e também institucional. É provável que os gestores tivessem algumas incertezas sobre a TI, não acreditando talvez que a alta gerência devesse envolver-se diretamente nas decisões referentes a essa área (os céticos). A partir da gestão 97-98, o processo de informatização ganha maior impulso. Nesse período, fica mais nítida a necessidade de mudanças, pois essa gestão já se inicia com grande mudança estrutural, fragmentando-se o poder até então concentrado na figura do diretor-geral. Cria-se uma Diretoria Executiva, composta por três diretores: superintendente, administrativo-financeiro e diretor médico. Busca-se uma administração mais profissional, nomeiando-se um professor universitário de administração de empresas para o cargo de diretor administrativo-financeiro, em substituição a um médico. Cria-se também um Setor de Recursos Humanos, dirigido por outro professor de administração. Os gestores acreditam que devem envolver-se fortemente nas decisões de TI e que a alta gerência deve iniciar projetos de TI (os envolvidos). Ao mesmo tempo, esses gestores participam da TI e se comprometem com ela, de forma integrada com as demais áreas (os positivos). A partir dessa fase, pode-se abordar o processo de mudança por uma perspectiva dita voluntarista (Wilson, 1992). Em outras palavras: há uma intervenção planejada, de forma que, partindo-se de um estado conhecido, pretende-se, passo a passo (incrementalismo lógico), chegar-se ao estado desejado. Esta abordagem equivale ao que Motta (1999) chama de intenção estratégica, significando uma deliberação racional de intervir na realidade organizacional visando à sua transformação, sendo a mudança essencialmente direcionada. 


\section{Descrição do Sistema de Informação}

É certo que se deve empregar alguma metodologia na escolha de um sistema de informação, considerando-se aspectos de plataformas de hardware e software, como também compatibilidade de custos iniciais e de manutenção, atualização e futuro tecnológico e disponibilidade dos serviços de assistência técnica.

O superintendente (gestão 97-98) não participou da escolha do software; mas, perguntado sobre os aspectos que mais devem pesar na escolha de um sistema hospitalar, ele respondeu:

"A verdade é que existem poucos sistemas de informática bons que se adeqüem à realidade hospitalar, porque quando um é bom em SUS, outro é bom em convênios. [...] Nenhum sistema é completo ou bom para uma gestão hospitalar porque ela é muito peculiar. Tem hospital que é variável ao extremo. [...] O sistema escolhido, pelo menos foi o único que engloba todas as áreas. Ele tem vários defeitos, mas engloba todas as áreas gerenciais: controle de materiais, pessoal, finanças etc." (Entrevista).

O sistema mais antigo implantado na organização é o de Contas a Pagar. Como ocorre em quase todas as empresas, a área financeira foi a primeira a ser informatizada. Houve também algumas iniciativas isoladas de informatização de alguns serviços, mas o uso da informática ocorria de modo estanque, sem integração. "São encontrados nos hospitais brasileiros, de modo geral, departamentos informatizados em graus diferentes entre si, sem obedecer a um planejamento criterioso prévio. Na prática, isto leva a uma pulverização de equipamentos que trabalham isolados, e à utilização de sistemas que não trocam informações entre si, dando aos recursos de informática uma utilidade apenas imediata e pessoal" (Komagata, 19__)

Quanto à empresa que implantou o sistema, trata-se aparentemente de uma empresa sólida, originária da região Sul do país, que atua no mercado há mais de dez anos e no Nordeste desde o final dos anos 80 . Neste estudo, referimo-nos a ela pelo nome fíctício de XYZ. O seu SIH é apresentado como seu principal produto e começou a ser desenvolvido em 1991. Apesar de ser uma empresa de porte considerável, a sua atuação inicial na organização estudada não foi planejada. Seus próprios dirigentes reconheceram, na ocasião de um evento para demonstração do SI, que a maneira como a XYZ entrou nesse hospital foi atípica, 
bem diferente do modo como normalmente costuma trabalhar. Em meio às criticas que recebeu dos funcionários, o diretor de atendimento da empresa afirmou que eles foram chamados, a princípio, para "apagar incêndio". De onde se pode deduzir que a contratação do sistema ocorreu numa situação de emergência.

O SIH em discussão, segundo seu fornecedor, tem como objetivo o pleno controle de uma instituição e atende a três áreas: administrativa, médica e acadêmica. É assim caracterizado pelo seu fornecedor:

. Totalmente modular.

. Apresenta forte integração entre os módulos.

. O controle é baseado no paciente.

- Concilia informações da área médica com a área administrativa.

. É de fácil utilização.

. É customizável (permite criar padrões ou perfis).

. Possui controle de versões.

No que tange às características tecnológicas, o ambiente computacional implantado no hospital em março de 1999 era o seguinte: o SI estava implantado em um servidor Pentium MMX com $166 \mathrm{MHz}, 128 \mathrm{Mb}$ (Megabytes) de memória RAM (Random Access Memory) e 2 HD (Hard Disk) de alta velocidade (padrão $\mathrm{SCSI}$ ), com $4 \mathrm{~Gb}$ (Gigabytes) de espaço físico. À época da coleta de dados, existiam 36 estações de trabalho conectadas à rede local. Os programas foram desenvolvidos na linguagem Clipper versão 5.2 e rodam em ambiente DOS. A rede local é gerenciada pelo software NetWare, versão 3.11 da Novell.

Já existe uma nova versão desse sistema que roda numa rede gerenciada pelo Windows NT (Microsoft), sendo os dados armazenados num banco de dados Oracle e a interface com o usuário desenvolvida para ambiente Windows. Essa nova versão já está implantada em outro hospital no Recife, porém o hospital estudado ainda não a implantou, porque isto implica custos adicionais com equipamentos.

\section{Os Problemas na Implantação e as Deficiências do Sistema de INFORMAÇÃO}


O superintendente (gestão 97-98) descreveu que, inicialmente, uma das principais dificuldades da implantação foi a falta de diálogo entre os implantadores do sistema (técnicos da empresa contratada) e os funcionários do hospital. Conforme Freitas et al. (1994), é natural que a implantação provoque alguns debates e que as mudanças afetem os atores do sistema de informações. Por conta disso, é incontestavelmente necessário fazer-se uma revisão das tarefas simultaneamente à implantação; no entanto, quase três anos após a implantação do sistema, pôde-se levantar na fase da coleta de dados, que os funcionários apontavam falhas claramente evidenciadas em vários módulos do sistema, ressaltando-se o SAME e a Farmácia.

Nem todos os problemas da implantação se devem, no entanto, a falhas do sistema. O processo decisório parece ter sido falho e talvez por isto não se tenham tomado certas medidas preventivas nem se tenham avaliado cuidadosamente as alternativas disponíveis. O hospital, por outro lado, não atendeu aos requisitos necessários para o funcionamento adequado do sistema. A rede local de computadores não ficou pronta dentro dos prazos previstos e alguns módulos do sistema foram implantados, inicialmente, de forma estanque, impossibilitando o compartilhamento das informações e implicando, às vezes, serviços repetidos. No caso da informatização dos postos de enfermagem, notou-se um problema infra-estrutural: existiam apenas três terminais para esse serviço. Os blocos cirúrgicos e os posto de enfermagem da ala de atendimento a pacientes particulares e de convênio não dispunham de estações conectadas à rede, sendo necessário o deslocamento dos auxiliares até os locais informatizados para realizarem a digitação. No início, isto gerou também problemas de aglomeração e bate-papos nesses postos.

O sistema possibilita também a entrada dos dados sobre a evolução do paciente (se teve febre, que medicação tomou etc.); mas este módulo não foi implantado devido ao pequeno número de estações de trabalho disponíveis, que mal atendem à demanda de digitação da prescrição médica. Por causa da falta de equipamentos, das limitações e das falhas do software, além das falhas iniciais na gerência do processo, perdeu-se certo controle da situação num primeiro momento da informatização, ficando assim comprometida a percepção das vantagens dessa tecnologia e gerando-se também dificuldades na sua aceitação.

\section{A Resistência à Implantação do Sistema de Informação}

Almeida (1995) identifica dois elementos que, a princípio, podem provocar resistência à implantação de um sistema de informação em uma empresa: a defici- 
ência técnica do sistema e as forças organizacionais (cultura da empresa, estrutura de poder e comportamento individual ou coletivo), considerando-se que o segundo elemento se tem mostrado mais delicado e difícil de gerenciar, porque envolve comportamento. A cultura organizacional predominante numa organização pode interferir na implantação de um sistema, bem como na avaliação de sua eficácia, podendo atuar em sentido favorável ou contrário ao esforço de introdução de um sistema (Almeida, 1995). A TI, hoje caracterizada pelo uso de redes, tende a tornar a estrutura de uma organização mais horizontal e descentralizada, pois as informações fluem mais rápida e facilmente do nível operacional até ao estratégico, podendo assim afetar a sua cultura organizacional.

O momento que a organização atravessava, quando foi introduzido o sistema, era bastante delicado. Diante da situação de crise, determinaram-se até cortes nas gratificações dos funcionários. Segundo um chefe de setor, apesar de não ser comum ocorrerem demissões na organização, alguns funcionários estavam com receio de perder seus empregos devido à informatização. Não havia o que Shirley (1976) analisa como uma abertura para as mudanças. Outro agravante é que não se estabeleceu, inicialmente, junto com a empresa contratada, um plano para a implantação.

No caso da informatização dos postos de enfermagem, notou-se também um forte componente cultural: o pessoal da área médica tende a reagir ao uso de computadores para fins meramente administrativos. Algumas auxiliares de enfermagem, de idade mais avançada, tiveram receio de usar o computador, além de considerarem o procedimento de digitação uma atividade burocrática. Todos foram convidados para treinamento no Setor de Informática, mas poucos compareceram. Enquanto os auxiliares de enfermagem mais antigos no hospital evitavam usar o sistema, encontrou-se uma auxiliar que, embora contratada há apenas um mês, já usava o sistema, mesmo sem ter recebido treinamento específico.

Os SI's computadorizados permitem um controle mais eficiente, que passa a ser exercido de forma invisível. Por conseguinte, as inovações tecnológicas apresentam grande potencial de interferir nas relações sociais e de poder entre os membros das organizações (Rosen e Baroudi, 1992). No caso de um SI em que as tarefas não são totalmente informatizadas, não se pode deixar de considerar os recursos humanos como um dos componentes desse sistema, como bem enfatiza Campos Filho (1994). Em geral, o desenvolvimento e implementação dos SI's acarretam impactos sobre as pessoas envolvidas, podendo tornar-se uma situação de difícil gerenciamento. A falta de treinamento foi um dos tópicos mais presentes nas entrevistas e conversas informais. Como conseqüência disso, muitos problemas aparentemente técnicos eram provocados por falha humana, pelo fato de os funcionários não saberem contornar certas situações simples. A ques- 
tão do treinamento dos recursos humanos é, portanto, de vital importância.

Nenhuma tecnologia por si só opera milagres em uma empresa. Se os usuários de um SI não o perceberem como ferramenta útil, por melhor que seja a tecnologia por trás desse sistema, os seus benefícios correm o risco de jamais aparecerem; por isto o SI deve ser promovido, devendo existir uma estratégia de marketing, conforme recomendam Freitas et al. (1994), para conscientizar os funcionários e incentivar a participação.

Todos os fatos descritos, agravados pela inexistência de manuais do sistema, induziram o uso mínimo dos recursos do SI, não se explorando todo o seu potencial. Por outro lado, esses fatos somados aos aspectos da cultura existente desencadearam nos funcionários uma forte resistência, praticamente generalizada, à empresa contratada e ao sistema. A partir da gestão 97-98 tentou-se resolver esses problemas, cobrando-se mais responsabilidades da empresa de informática. Nas palavras do próprio superintendente "não se mete de goela a baixo um sistema de informática numa instituição" (Entrevista). Segundo relatos do superintendente, os funcionários do hospital desenvolveram uma espécie de "ódio" à empresa contratada, a ponto de só se referirem a ela como "essa tal de XYZ".

Apesar de todos as dificuldades iniciais, a partir da gestão 97-98, a intervenção mais direta dos gestores no processo veio dar um novo rumo à informatização, tornando-a uma questão prioritária, pois o processo era irreversível, uma vez que já se havia investido uma quantia razoável de tempo e dinheiro nesse projeto.

\section{Descrição da Amostra Estudada}

Neste estudo, trabalhou-se praticamente com toda a população de usuários, exceto no caso dos auxiliares de enfermagem, pois a grande maioria não devolveu os questionários, alegando falta de tempo para responder.

Faz-se agora um breve relato da amostra estudada. Ela é composta predominantemente por funcionários da área administrativa, cerca de $76 \%$, até porque se trata de um sistema desenvolvido para auxiliar na gestão administrativa. A grande maioria dos que operam o sistema, cerca de $75 \%$, são do sexo feminino. A amostra é composta relativamente de jovens, pois um pouco mais da metade $(51,6 \%)$ possui menos de 30 anos. O nível de escolaridade da amostra é considerado bom, pois $65,6 \%$ dos usuários possui o segundo grau (menor grau de instrução dos respondentes) e 34,5\% possui curso superior completo. A grande maioria dos sujeitos da amostra (cerca de 64,1\%) está na organização há menos de 5 
anos.

O nível de conhecimento e prática sobre informática foi cruzado com a idade dos usuários, e observou-se que $44 \%$ dos que afirmam ter conhecimentos médios e $83,3 \%$ dos que afirmam ter muitos conhecimentos sobre informática têm até 30 anos de idade. Este resultado era esperado, uma vez que, na realidade do atual mercado de trabalho, exige-se dos jovens cada vez mais habilidades com o computador para ingressarem nas empresas. O nível de conhecimento e prática sobre informática foi cruzado também com o tempo de serviço, encontrando-se que $55,6 \%$ dos que afirmam ter conhecimentos médios e $100 \%$ dos que afirmam ter muitos conhecimentos sobre informática têm até 5 anos de serviço no hospital; portanto os funcionários mais jovens e há menos tempo no hospital são os que afirmaram possuir mais conhecimento sobre informática.

Esses resultados podem ser um indicador de que os funcionários mais antigos no hospital e os que estão nas faixas etárias mais altas não estão conseguindo atualizar-se nessas novas tecnologias. Isto talvez se explique pelo fato de o uso dos computadores ser ainda incipiente nesse hospital, não havendo microcomputadores em todos os postos de trabalho nem treinamento sistemático dos recursos humanos, ou seja, a organização ainda não tem formado uma cultura de informática, podendo-se dizer que o uso do computador ainda não foi incorporado às práticas de trabalho (Campos Filho, 1994).

\section{A Eficácia do Sistema de Informação}

As 15 perguntas referentes à dimensão satisfação do usuário tiveram um coeficiente de correlação de Pearson de 0.78 com a pergunta de fechamento satisfação global com o sistema, significativa ao nível 0.05. As 9 perguntas referentes à dimensão utilidade do sistema tiveram um coeficiente de correlação de Pearson de 0.63 , com a pergunta de fechamento utilidade global do sistema significativa ao nível 0.05 .

No presente estudo, portanto, o instrumento de pesquisa mostrou-se consistente, no que se refere à associação entre os escores que representam as percepções dos usuários (soma dos pontos atribuídos a cada item) e suas respectivas perguntas de fechamento (satisfação do usuário e utilidade do sistema).

Na Tabela 1 são exibidas as médias, em ordem decrescente, dos itens referentes à satisfação do usuário. Na escolha de um sistema, é freqüente dar-se uma ênfase muito forte às questões de interfaces gráficas do sistema com o usuário, 
em detrimento até da funcionalidade. Neste caso, embora o SI implantado não tenha uma interface gráfica (GUI), sendo orientado por menus, os usuários demonstram satisfação na interação com ele, pois os itens referentes a essa questão (1, 2, 5 e 9) estão entre os de melhor avaliação. Quanto aos itens 3 e 7 (os piores na avaliação), a explicação é que não existem telas de Help nem manuais do sistema, sendo todas as dúvidas esclarecidas pelo pessoal do Setor de Informática que, quando não aptos a esclarecer ou resolver os problemas, recorrem ao apoio técnico do fornecedor do software, que se mostrou deficiente. Quanto ao item 4, foi constatado que o sistema deixa entrar muitos dados inconsistentes, e o tempo de resposta (item 15) não é tão bom por causa dos problemas de índices dos arquivos clipper (.DBF), que precisam ser periodicamente reindexados.

Tabela 1: Médias dos Itens da Medida Satisfação do Usuário

\begin{tabular}{|c|c|c|c|}
\hline ORDEM & ITEM & SATISFAÇÃO DO USUÁRIO & MÉDIA \\
\hline 1 & 2 & Navegação pelo sistema & 4.079 \\
\hline 2 & 1 & Acesso ao sistema & 4.078 \\
\hline 3 & 13 & $\begin{array}{l}\text { Segurança do sistema (quanto a acessos } \\
\text { indevidos) }\end{array}$ & 3.587 \\
\hline 4 & 5 & Clareza das mensagens & 3.556 \\
\hline 5 & 6 & Precisão das informações & 3.355 \\
\hline 6 & 9 & Inteligibilidade (clareza das telas e listagens) & 3.279 \\
\hline 7 & 10 & $\begin{array}{l}\text { Adequação na apresentação das } \\
\text { informaçôes }\end{array}$ & 3.276 \\
\hline 8 & 12 & Conformidade (atende às especificações) & 3.238 \\
\hline 9 & 4 & Consistência dos dados de entrada & 3.000 \\
\hline 10 & 8 & Quantidade de informações & 2.935 \\
\hline 11 & 14 & Qualidade do suporte (apoio técnico) & 2.917 \\
\hline 12 & 15 & Tempo de resposta do sistema & 2.891 \\
\hline 13 & 11 & Freqüência de atualização das informações & 2.797 \\
\hline 14 & 3 & Telas de Help (ajuda) & 1.000 \\
\hline 15 & 7 & Qualidade dos manuais & 1.000 \\
\hline & & Média Geral $\Rightarrow$ & 2.999 \\
\hline
\end{tabular}


A Tabela 2 mostra as médias, em ordem decrescente, dos itens referentes à utilidade do sistema. Na opinião dos usuários, os aspectos de melhor utilidade do sistema são quanto à melhoria do fluxo de trabalho, à redução no tempo de execução das tarefas e utilidade das saídas para tomada de decisão; portanto esses resultados são muito coerentes com o que se espera de um sistema de informação.

\section{Tabela 2: Médias dos Itens da Medida Utilidade do Sistema}

\begin{tabular}{c|c|l|c} 
ORDEM & ITEM & UTILIDADE DO SISTEMA & MÉDIA \\
\hline 1 & 3 & Melhoria no fluxo de trabalho & 4.050 \\
\hline 2 & 6 & Redução no tempo de execução das tarefas & 3.852 \\
\hline 3 & 1 & $\begin{array}{l}\text { Utilidade das saídas para tomada de } \\
\text { decisões }\end{array}$ & 3.638 \\
\hline 4 & 2 & Mellor utilização do tempo & 3.500 \\
\hline 5 & 9 & Melhoria no ambiente de trabalho & 3.492 \\
\hline 7 & 5 & Autonomia em relação aos outros & 3.400 \\
\hline 8 & 8 & Redução de erros & 3.355 \\
\hline 9 & 4 & Disponibilidade do sistema (estar no ar) & 3.306 \\
\hline & & &
\end{tabular}

Para operarem o sistema, os funcionários são treinados em coisas específicas, voltadas ao desempenho de suas funções, não sendo necessário treinamento em microinformática, tal como o sistema DOS e/ou Windows, porque a interface de comunicação do sistema com o usuário é orientada por menus. Muitas estações de trabalho não possuem disco rígido, sendo úteis apenas para uso do sistema. Vendo-se por este ângulo, o SI não proporciona uma oportunidade de adquirir novos conhecimentos de informática, explicando talvez a baixa utilidade do sistema, quanto ao item aprendizagem de novos conhecimentos; mas, por outro lado, o sistema de informação emite alguns relatórios gerenciais que poderiam ser interpretados como fontes de aprendizagem.

Quanto à utilidade do sistema na redução de erros, vale ressaltar que, nos dados qualitativos, se registrou muitas queixas quanto às falhas do sistema, principalmente no módulo de Controle de Estoques (Almoxarifado e Farmácia), prejudicando assim a sua confiabilidade. 
$\mathrm{Na}$ amostra em estudo, as respostas de 44 usuários (68\% da amostra) somaram escores de eficácia em torno de um desvio padrão, significando que a maior parte dos usuários atribuiu ao sistema uma eficácia média. Com base na análise qualitativa, porém, esperava-se uma avaliação muito negativa, porque os fatores subjetivos, não inerentes ao próprio sistema de informação, podem afetar a percepção da sua eficácia. Acredita-se que, se não existissem tantos dos problemas aqui relatados, a eficácia atribuída ao SI em estudo poderia ter sido mais bem avaliada.

Agrupando-se os usuários por setores em três grupos, G1 (Departamento de Controle e Prevenção, SAME e Recepções), G2 (Serviço de Enfermagem-Auxiliares) e G3 (demais setores), pôde-se notar que no grupo G1, a eficácia do SI foi mais bem avaliada, pois $48,3 \%$ dos usuários desse grupo atribuíram níveis altos de eficácia ao SI (intervalos médio-superior e superior). Verificou-se que o grupo G1 é o que mantém maior contato com a informática, possui um bom grau de escolaridade, sendo formado por jovens abaixo de 30 anos, em sua maioria, e que são relativamente novos na organização. Embora não tenhamos investigado, isto parece indicar uma relação favoravelmente positiva entre essas variáveis e a avaliação de eficácia. Por meio dos dados qualitativos encontrou-se que o grupo G2 se mostrou muito reativo às mudanças e apegado às formas tradicionais de trabalho. O grupo G3 foi onde mais se detectou insatisfação e problemas técnicos com o sistema (vide Tabela 3).

Tabela 3: Eficácia do Sistema de Informação

\begin{tabular}{|l|c|c|c|c|c|c|c|c|}
\hline \multirow{2}{*}{$\begin{array}{c}\text { Níveis de } \\
\text { Eficácia }\end{array}$} & \multicolumn{7}{|c|}{ Grupos de Usuários } \\
\cline { 2 - 10 } & $\mathrm{F} 1$ & $\%$ & $\mathrm{~F}$ & $\%$ & $\mathrm{~F}$ & $\%$ & $\mathrm{~F}$ & $\%$ \\
\hline De 24-42 & 0 & 0,0 & 0 & 0,0 & 4 & 14,8 & 4 & 6,3 \\
\hline De 43-61 & 3 & 10,3 & 2 & 25,0 & 6 & 22,2 & 11 & 17,2 \\
\hline De 62-80 & 12 & 41,4 & 3 & 37,5 & 13 & 48,1 & 28 & 43,8 \\
\hline De 81-100 & 12 & 41,4 & 3 & 37,5 & 3 & 11,1 & 18 & 28,1 \\
\hline De 101-120 & 2 & 6,9 & 0 & 0,0 & 1 & 3,7 & 3 & 4,7 \\
\hline Total & 29 & 100 & 8 & 100 & 27 & 100 & 64 & 100 \\
\hline
\end{tabular}




\section{A Relação Entre a Eficácia do Sistema de Informação e a Percepção de Melhoria na Qualidade do Atendimento ao PaCiente}

Na Tabela 4 nota-se que dos 64 respondentes, 51 usuários (79,7\%) perceberam uma melhoria na qualidade do atendimento ao paciente. Pode-se dizer que, de modo geral, esse objetivo foi percebido como tendo sido alcançado. Apesar de apresentar algumas falhas técnicas e do processo de implantação conturbado, o sistema contribuiu para a percepção do alcance do objetivo melhoraria na qualidade do atendimento.

Tabela 4: Percepção de Mudança na Qualidade no Atendimento ao Paciente

\begin{tabular}{|l|c|c|c|c|c|c|c|c}
\hline \multirow{2}{*}{$\begin{array}{c}\text { Mudança ma } \\
\text { Qualidade Percebida } \\
\text { do Atendimento ao } \\
\text { Paciente }\end{array}$} & \multicolumn{2}{|c|}{ G1 } & \multicolumn{2}{|c|}{ G2 } & \multicolumn{2}{c}{ G3 } & \multicolumn{2}{c}{ Total } \\
\cline { 2 - 10 } & F & $\%$ & F & $\%$ & F & $\%$ & F & $\%$ \\
\hline Não respondeu & - & - & - & - & 1 & 3,7 & 1 & 1,6 \\
\hline Não mudou & 3 & 10,3 & - & - & 7 & 25,9 & 10 & 15,6 \\
\hline Piorou & - & - & 2 & 25,0 & - & - & 2 & 3,1 \\
\hline Melhorou & 26 & 89,7 & 6 & 75,0 & 19 & 70,4 & 51 & 79,7 \\
\hline Total & 29 & 100 & 8 & 100 & 27 & 100 & 64 & 100
\end{tabular}

Mas até que ponto essa percepção de melhoria está relacionada à eficácia do sistema? Aplicou-se a ferramenta Teste-T: duas amostras presumindo variâncias equivalentes do Excel 97, para verificar se a diferença de médias da variável melhoria percebida na qualidade do atendimento entre os grupos é significativa. A diferença foi achada significativa entre os grupos G1 e G2 a um nível de confiança de $90 \%\left(t_{0}=1,851640>t_{c}\right.$ bicaudal $\left.=1,697260\right)$.

No grupo G1 a percepção de melhoria foi mais acentuada, porque, conforme a Tabela 5, se observa que nesse grupo a maioria dos usuários percebeu níveis de melhoria na qualidade do atendimento acima da média (valores 4 e 5 da escala). Isto ocorreu principalmente no Departamento de Controle e Prevenção. Foi também no grupo G1 que o SI obteve os maiores níveis de eficácia (vide Tabela 3). Usando-se a ferramenta Regressão do Excel 97, num nível de confiança de 95\%, 
encontrou-se uma correlação significativa $\mathrm{r}=0,5011$ entre os escores de eficácia do sistema de informação e o nível de melhoria percebida no atendimento ao paciente, apenas nos usuários do grupo G1 (conforme a Tabela 6). Isto talvez se deva ao fato de o grupo G1 lidar mais diretamente com os pacientes nos serviços administrativos e ser formado por pessoas mais jovens, mais recentes na organização, bem treinadas e onde se encontrou o maior grau de conhecimento e prática em microinformática. Ruiz (1983, p. 59) diz que "correlações da ordem de $0,40,0,35$ e até 0,25 são freqüentemente citadas como sugestivas de influência de uma variável na outra". Isto nos leva a dizer que, no grupo G1, a variabilidade da eficácia do SI é explicada pelo nível de melhoria percebida na qualidade do atendimento em torno de apenas $25 \%$.

\section{Tabela 5: Níveis de Melhoria Percebida na Qualidade do Atendimento}

\begin{tabular}{|c|c|c|c|c|c|c|c|c|}
\multirow{2}{*}{$\begin{array}{c}\text { Níveis de } \\
\text { Melhoria }\end{array}$} & \multicolumn{8}{|c|}{ Grupos de Us uários } \\
\cline { 2 - 9 } Percebida & \multicolumn{2}{|c|}{ G1 } & \multicolumn{2}{|c|}{ G2 } & \multicolumn{2}{|c|}{ G3 } & \multicolumn{2}{|c|}{ Total } \\
\cline { 2 - 10 } & F & $\%$ & F & $\%$ & F & $\%$ & F & $\%$ \\
\hline $\mathbf{1}$ & 1 & 3,8 & 2 & 33,3 & 1 & 5,3 & 4 & 7,8 \\
\hline $\mathbf{2}$ & 2 & 7,7 & 1 & 16,7 & 0 & 0,0 & 3 & 5,9 \\
\hline $\mathbf{3}$ & 9 & 34,6 & 1 & 16,7 & 9 & 47,4 & 19 & 37,3 \\
\hline $\mathbf{4}$ & 6 & 23,1 & 1 & 16,7 & 5 & 26,3 & 12 & 23,5 \\
\hline $\mathbf{5}$ & 8 & 30,8 & 1 & 16,7 & 4 & 21,1 & 13 & 25,5 \\
\hline Total & 26 & 100 & 6 & 100 & 19 & 100 & 51 & 100 \\
\hline
\end{tabular}

Este estudo sugere que nos setores do grupo G1, os funcionários perceberam a questão do atendimento do paciente como um objetivo operacional (aquele que eles estão buscando nas suas tarefas diárias) e, como o SI se mostrou ferramenta útil para o desempenho de suas funções, houve uma congruência com o objetivo formal declarado pelo superintendente. Nos outros dois grupos (G2 e G3), embora os funcionários tenham respondido que houve melhoria no atendimento, o nível de melhoria não pode ser explicado pela eficácia do sistema. Poder-se-ia dizer que o sistema não se mostrou eficaz para os objetivos desses grupos. O grupo G2 (auxiliares de enfermagem) está mais preocupado com a qualidade do serviço médico propriamente dito. Os dados qualitativos mostraram que, na realidade, a maioria desses profissionais não gosta de usar o sistema, alegando tratar-se de uma tarefa burocrática. O grupo G3, além de não lidar diretamente com os pacientes, foi o que mais se mostrou insatisfeito com a eficá- 
cia do sistema, devido aos problemas técnicos do software.

\section{Tabela 6: Resultado da Análise de Regressão}

\begin{tabular}{|c|c|c|c|c|}
\hline Estatística & TODOS & GRUPO G1 & GRUPO G2 & GRUPO G3 \\
\hline $\mathrm{R}$ múltiplo & 0,297542211 & 0,501121317 & 0,155923616 & 0,16909731 \\
\hline R-quadrado & 0,088531368 & 0,251122574 & 0,024312174 & 0,0285939 \\
\hline R-quadrado ajustado & 0,069929967 & 0,219919348 & $-0,219609782$ & $-0,028547635$ \\
\hline Erro padrão & 14,94083262 & 13,06052203 & 15,03579063 & 17,09907011 \\
\hline Observações & 51 & 26 & 6 & 19 \\
\hline
\end{tabular}

Na implantação de um SI, é importante mostrar aos usuários, sistematicamente, as vantagens que eles podem tirar do uso de um sistema para a realização de suas tarefas. Todavia, se o sistema não demonstra ser eficaz para se atingir os objetivos ditos operacionais, o grau em que se percebe a realização de outros objetivos pode não ser significativo. Fica evidente então a necessidade de se estabelecer bons canais de comunicação para que, a partir dos objetivos estabelecidos para a informatização, haja transparência no processo de implantação, de forma que as pessoas possam vir a colaborar com o projeto, mesmo que não vejam benefícios imediatos em suas atividades.

\section{Considerações Finais}

Ao se analisar os problemas existentes neste estudo, quanto ao processo de implantação de um sistema de informação, tomando-se por base as entrevistas e as opiniões informais das pessoas (métodos qualitativos), poder-se-ia chegar a conclusões precipitadas, quanto ao sucesso ou fracasso desse projeto, deduzindo-se, à primeira vista, tratar-se de um caso não exitoso. A avaliação qualitativa dos usuários pode não refletir as qualidades inerentes de um SI, devido aos problemas eventualmente ocorridos durante o processo de implantação. Mediante os questionários, os usuários emitiram opiniões mais criteriosas sobre as qualidades e defeitos do sistema, utilizando uma escala de valores. Esses dados, tratados por métodos estatísticos, colocam em dúvida as conclusões iniciais de que o sistema não seria eficaz, pois, pelo menos no estrato G1 (45\% da amostra), os 
resultados estatísticos mostram uma eficácia satisfatória (vide Tabela 3).

A conclusão final, quanto à eficácia do SI implantado, é que tal SI tem problemas, precisou e/ou precisa ainda de ajustes, mas foi considerado de eficácia média, atingindo 3 pontos (aproximação de 2.99) quanto à satisfação dos usuários e 4 pontos (aproximação de 3.53) quanto à sua utilidade, em uma escala Likert de cinco pontos. O processo de desenvolvimento e implantação desse sistema, à luz da literatura, demonstrou ter sido traumático e cheio de falhas, tanto no que diz respeito à forma de a empresa contratada intervir no ambiente organizacional do hospital, quanto à falta de planejamento do hospital e da empresa de informática. Somam-se a isto os problemas de infra-estrutura e a falta do treinamento adequado e sistemático dos recursos humanos, além de alguns aspectos culturais. Neste estudo, estiveram presentes os dois elementos que, segundo Almeida (1995), podem provocar resistência à introdução de um SI: a deficiência técnica do sistema e as forças organizacionais.

Os resultados desta pesquisa sugerem que, para ter maior nível de objetividade, a avaliação de um SI deve ser feita após certo período de consolidação, pois as dificuldades iniciais e o pouco tempo de uso podem levar a avaliações precipitadas, pelo fato de se ter ainda pouca percepção dos resultados do sistema, principalmente, os positivos. Os negativos são percebidos rapidamente.

Neste trabalho, ressaltou-se que não se deve perder o foco na informação em detrimento de deslumbres com a tecnologia em si mesma (Shiozawa, 1993; Mcgee, 1999), devendo o uso da TI estar em consonância com as reais necessidades dos usuários e com os objetivos organizacionais, sendo estes o ponto de partida para a adoção dos sistemas de informação (Campos Filho, 1994).

Nem todos os benefícios são tangíveis, isto é, quantificáveis economicamente. A exemplo do objetivo selecionado neste estudo, melhoria na qualidade percebida do atendimento ao paciente; todavia os objetivos intangíveis são igualmente importantes. Este estudo sugere que um SI é considerado eficaz, à medida que é percebido como elemento que contribui para o alcance dos objetivos organizacionais. Daí a importância de que a visão das reais necessidades da informatização seja partilhada por todos e que, a partir disto, sejam definidos objetivos claros, com transparência e, sobretudo, com coerência. Não se deve escolher um sistema por critérios políticos, mas antes de tudo técnicos. Deve-se ainda evitar importar soluções que se confrontem muito fortemente com a cultura predominante na organização, pois quanto mais um sistema atua contra a cultura organizacional, menos chances tem o projeto de ser um sucesso. 


\section{Biblografia}

ALBERTIN, A. L.

Administração de informática e a organização. Revista de Administração de Empresas, v. 34, n .6, p. 60-72, set. 1995.

\section{ALBRECHT, K.}

Serviços internos: como resolver a crise de liderança do gerenciamento de nível médio. São Paulo: Pioneira, 1994.

\section{ALMEIDA, F. C.}

Atores e fatores na introdução de um sistema de informação. Revista Brasileira de Administração Contemporânea, v. 1, n. 4, p.177-192, set. 1995.

ANDRADE, D. G. DE.

$A$ influência da percepção de mudança organizacional sobre a avaliação da eficácia de um sistema de informação (SI). Recife, 2000. Dissertação (Mestrado) - Departamento de Ciências Administrativas, Universidade Federal de Pernambuco.

BERWICK, D. M. et al.

Melhorando a qualidade dos serviços médicos hospitalares e da saúde. São Paulo: Makron Books, 1994.
BEUREN, I. M.

Gerenciamento da informação: um recurso estratégico no processo de gestão empresarial. São Paulo: Atlas, 1998.

BRITO, M. J. DE;

ANTONIALLI, L. M.;

SANTOS, A. C. DOS.

Tecnologia da informação e processo de gestão em uma organização cooperativa: um enfoque estratégico. Revista de Administração Contemporânea, v. 1, n. 3, p. 77-95, set./dez. 1997.

BRODEBECK, A. F.

Avaliação da qualidade da informação nos sistemas de informações e de apoio à decisão - um estudo introdutório. Revista Brasileira de Administração Contemporânea, v. 1, n. 4, p. 73-88, set. 1995 .

CAMPOS FILHO, M. P.

Os sistemas de informações e as modernas tendências da tecnologia e dos negócios. Revista de Administração de Empresas, v. 34, n. 6, p. 33-45, nov./dez. 1994. 
DIAS, D. DE S.

$O$ sistema de informação e a empresa. Rio de Janeiro: LTC, 1985.

Eficácia de sistemas de informação, participação do usuário e mudança organizacional. In: XVII ENCONTRO ANUAL DA ANPAD (1993: Salvador). Anais... Salvador: ANPAD, 1993. v. 2. p. 163-172.

FALK, J. A.;

CARVALHO, E.

Qualidade de serviços na área hospitalar. In: VIEIRA, M. M. F.; OLIVEIRA, L. M. DE. (Orgs.) Administração contemporânea: perspectivas estratégicas. São Paulo: Atlas, 1999.

FREITAS, H. M. R. DE et al.

Avaliação de sistemas de informações. Revista de Administração, v. 29 , n. 4 , p. 36-55, out./ dez. 1994.

\section{GARVIN, D. A.}

Gerenciando a qualidade: a visão estratégica e competitiva. São Paulo: Qualitymark, 1992.

\section{GUROVITZ, H.}

Fato: bilhões de dólares são torrados em investimentos inúteis em tecnologia. Questão: dá para se defender? Revista Exame, ano 30, n. 12, jun. 1997.
ILHA, J. O.

O registro clínico informatizado no hospital. [online] Disponível na Internet via WWW.URL: http:// www.brasil.bem.nw.dc.us /NIB/ informed. Revista Informédica, v. 2, n. 10, p. 5-12, 1994.

JOHANSTON, H.

Sistemas de informação hospitalar: presente e futuro. [online] Disponível na Internet via W W W. U R L : h t t p : / / www.brasil.emb.nw.dc.us/NIB/ informed. Revista Informédica, v. 1, n. 2, p. 5-9, 1993.

KOMAGATA, H.

A seleção de um sistema de informação hospitalar. [online]. Disponível na Internet via W W W. U R L : h t t p : // www.henet.usp.br/forum/ selecao.htm. 19--.

LAPPONI, J. C.

Estatística usando Excel 5 e 7. São Paulo: Lapponi Treinamento e Editora, 1997.

MARINHO, M. DE S. C.

A questão dos objetivos nas organizações. Revista de Administração de Empresas, v. 30, n. 2, p. 5-22, abr./jun. 1990. 
MCGEE, J. V.

Gerenciamento estratégico da informação: aumente a competitividade e a eficiência de sua empresa utilizando a informação como uma ferramenta estratégica. 4. ed. Rio de Janeiro: Campus, 1999.

MONTEIRO, R. C.

A pesquisa qualitativa como opção metodológica. Pró-Posições, n. 5, ago. 1991.

MOTTA, P. R.

Transformação organizacional: a teoria e a prática de inovar. Rio de Janeiro: Qualitymark, 1999.

NEVES, J. L.

Pesquisa qualitativa - características, usos e possibilidades. Cadernos de Pesquisa em Administração, v. 1, n. 3, p. 103-113, 1996.

PRESSMAN, R. S.

Engenharia de software. São Paulo: Makron Books, 1995.

PROENÇA, R. P. DA C.

Mudança e adaptação organizacional: o caso do Hospital Nereu Ramos. Revista Brasileira de Administração Contemporânea, v. 1 , n. 6 , p. 329-348, set. 1995.
REMENYE, D.

Achieving maximum value from information systems: a process approach. New York: John Wiley \& Sons, 1998.

RICHARDSON, R. J.

Pesquisa social: métodos e técnicas. São Paulo: Atlas, 1989.

ROCHA, A. R. C.

Qualidade de software. [online] Disponível na Internet via W W W. U R L : h t t p : // www.agrosoft.com.br/concurso/ ana. Workshop em Qualidade de Software Agropecuário, Juiz de Fora, 1998.

ROSEN, M.;

BAROUDI, J.

Computer-based technology and the emergence of new forms of managerial control. In: Skill and consent: contemporary studies in the labour process. New York: Routledge, 1992. p. 213-234.

RUIZ, F.

Estatítica básica aplicada à saúde. Brasília: Centro de Documentação do Ministério da Saúde, 1983. 
SABBATINI, R. M. E.;

ORTIZ, J.

MEDSARR: um sistema para a informatização integrada de clínicas. [online] Disponível na Internet via WWW.URL: http:// www.brasil.bem.nw.dc.us/NIB/ informed. Revista Informédica, v. 2, n. 10, p. 5-12, 1994.

SHIOZAWA, R. S. C.

Qualidade no atendimento e tecnologia de informação. São Paulo: Atlas, 1993.

SHIRLEY, R. C.

Um modelo para análise de mudança organizacional. Revista de Administração de Empresas, v. 16, n. 6, p. 37-43, 1976.

\section{SIEGEL, S.}

Estatística não-paramétrica para as ciências do comportamento. São Paulo: McGraw-Hill, 1995.

SOCIEDADE PERNAMBUCANA DE COMBATE AO CÂNCER.

50 anos de amor à vida. [s.1.], Editora Brasileira de Guias Especiais, 1995.
SPIEGEL, M. R.

Estatística. 2. ed. São Paulo: McGraw-Hill, 1985.

SZILAGYI JR., A. D.;

WALLACE JR., M. J.

Organizational behavior and performance. 5. ed. [S.1.]: HarperCollins, 1990.

TORRES, N. A.

Competitividade empresarial com a tecnologia da informação. São Paulo: Makron Books, 1995.

VASSALLO, C.

Por que os preços cobrados pelos hospitais brasileiros são tão caros? Revista Exame, São Paulo, ano 30, n. 10, maio, 1997.

WILSON, D. C.

A strategy of change: concepts and controversies in the management of change. New York: Routledge, 1992.

YIN, R. K.

Case study research: design and methods. 2. ed. London: Sage Publications, 1994. v. 5. 